\title{
DESIGN AND ANALYSIS OF HIGH-EFFICIENT DRIVER MODEL FOR LED LUMINAIRES
}

\author{
Onur Akalp ${ }^{1}$, Harun Ozbay ${ }^{2}$, and Serhat Berat Efe ${ }^{2}$ \\ ${ }^{1}$ Graduate School of Natural and Applied Sciences, Bandirma Onyedi Eylül University, Turkey \\ ${ }^{2}$ Department of Electrical Engineering, Bandırma Onyedi Eylül University, Turkey \\ E-mail:sefe@bandirma.edu.tr
}

\begin{abstract}
LED luminaires need a driver circuit for working properly. Most of the drivers have disadvantages such as losses during operation. This issue becomes more important while supplying with limited sources such as renewables. To overcome the problem, this study proposes a novel energy efficient driver for LED luminaires based on zero voltage switching (ZVS) single-ended primary inductance converter (SEPIC) technology. Driver and hence luminaires were designed to be fed from photovoltaic (PV) panels. In addition, an adaptive MPPT algorithm was developed to obtain optimum efficiency from supply system. SEPIC approach was preferred for MPPT application due to its advantages such as non-reversing polarity. This feature allows energy efficiency in corporation with ZVS. Proposed model was designed under PSIM platform with all components; PV panels, ZVS, SEPIC, and LED luminaires. A detailed analysis was performed by using system graphs under various operating conditions as different irradiance levels. Results show that proposed model is energy efficient and modular because of its low-volume structure. Therefore the model can lead smaller driver circuits with minimum losses.
\end{abstract}

Keywords: energy efficiency, LED, soft switching, SEPIC, PV system

\section{INTRODUCTION}

Environmental effects of fossil fuels and the global climate balance issue have accelerated the studies on environmental-friendly energy sources. In this context, researches on renewable energy systems have increased in recent years. Photovoltaic (PV) systems are quiet and clean way to convert the sunlight into electrical energy [1]. Solar energy is a natural and maintenance-free resource. PV modules are used to convert the solar energy into electrical energy. These modules are created by arranging solar cells in series and parallel [2].

On the other hand, it is also an important issue to save the energy demand and increase the energy efficiency. Since approximately $25 \%$ of electrical energy is used for lighting purposes in the world, researchers are looking for solutions to provide the same lighting level in more economical ways without reducing the lighting quality. Therefore, nowadays light emitting diode (LED) technology has become the most interesting subject.

LEDs, which are preferred because of their features such as making efficient lighting with less energy consumption, become more widespread for the illumination applications [3-8]. LED illumination is not only used in the night but also applied and used in offices, schools, industrial installations which are active during daylight [9]. In general, PV supplied lighting systems are preferred for illumination in such buildings. While PV panels have low efficiency [10], obtained energy should be used in most efficient way, which is one of the main pur- 
pose of proposed zero voltage switching (ZVS) single-ended primary inductance converter (SEPIC) design.

However, LEDs need a driver to operate [11]. Losses due to drivers are one of the biggest drawbacks of LEDs and this causes low efficiency. In addition, such drivers are formed in larger volumes for necessity of bigger cooling devices because the illumination level of LEDs affected by temperature $[12,13]$. The proposed design also focused to overcome this problem.

A constant output cannot be obtained in solar panels, because the solar radiation and temperature of the environment constantly changes during the day. In order to obtain maximum gain from this variable energy, instantaneous maximum power point tracking (MPPT) should be performed [14, 15]. Although there are different power tracking methods in applications, the Perturb and Observe ( $\mathrm{P} \& \mathrm{O})$ method is the most common and popular MPPT method due to its simple and easy application [16]. In this method, output current and output voltage of PV modules are monitored. The operating point is changed by decreasing and increasing the duty cycle of the driver circuit with fixed steps [17]. The choice of this fixed step size is the main problem of the MPPT method. To overcome this problem, researchers have developed an auto-scaling step size MPPT structure. The most used method in practice is the voltage derivative [18].

SEPIC can be preferred for MPPT application due to its advantages such as non-reversing polarity, ease of driving the semiconductor switch and low input current oscillation [19]. Soft switching is performed using the resonant coil and capacitor to reduce the switching loss on the semiconductor switch of the converter. In hard switching, shortterm energy loss occurs because the voltage value at the switching point is not taken into account. In soft switching, switching occurs when the voltage on the switch reaches zero. Thus, energy loss is minimized [20]. Therefore, ZVS is one of the most reasonable soft switching methods.

In most conventional converter circuits, if a higher or lower voltage level is to be obtained at the output than the input, it is difficult to achieve a wide operating range while providing high efficiency. Due to the high energy storage requirements in circuits with low switching frequencies, it is difficult for circuits to downsize and respond quickly. Therefore, it is necessary to design circuits that re- duce energy storage requirements, are small in size and expand the efficient operating range [21].

Due to aforementioned reasons, in this study a novel approach for energy efficient LED driver circuit was proposed. In this context, obtaining the maximum power from the PV panels using the MPPT method was achieved by ZVS SEPIC converter with a scaled-down circuit at higher frequencies compared to conventional converters. Thus, a highly efficient driver system has been designed for LED lighting systems.

Manuscript consist of four sections. The literature review and main contribution of paper were given in introduction section, while LED driver based on ZVS SEPIC that supplied by PV panel was detailed in section two. Third section has included the simulation results and discussions, and finally manuscript was concluded in fourth section.

Main contribution of this paper can be given as follows:

- As there are various studies in literature about ZVS SEPIC, in this study an adaptive PI controlled P\&O MPPT algorithm was used and, in addition, frequency was controlled and regulated dynamically;

- Proposed system was designed to generate embedded code for TMS320F28335 DSP processor, which allows a low volume design and precise controlling ability;

- Temperature issue and cooler dimensions are the most important problems for LED illumination systems, therefore driver circuit losses and consequently temperature problems were minimized by this design with the advantage of ZVS SEPIC.

\section{PV POWERED ZVS SEPIC DRIVER DESIGN}

According to the main purpose of study, LED luminaire driver that based on PV powered ZVS SEPIC was designed. The design process was detailed in following sections which given as block diagram in Fig. 1.

\subsection{ZVS SEPIC Model}

The switching performance of semiconductor elements can be increased by adding resonant circuits to rigid switched pulse width modulated (PWM) converters. The resonant elements consist of a parallel capacitor and a series inductor attached to the 


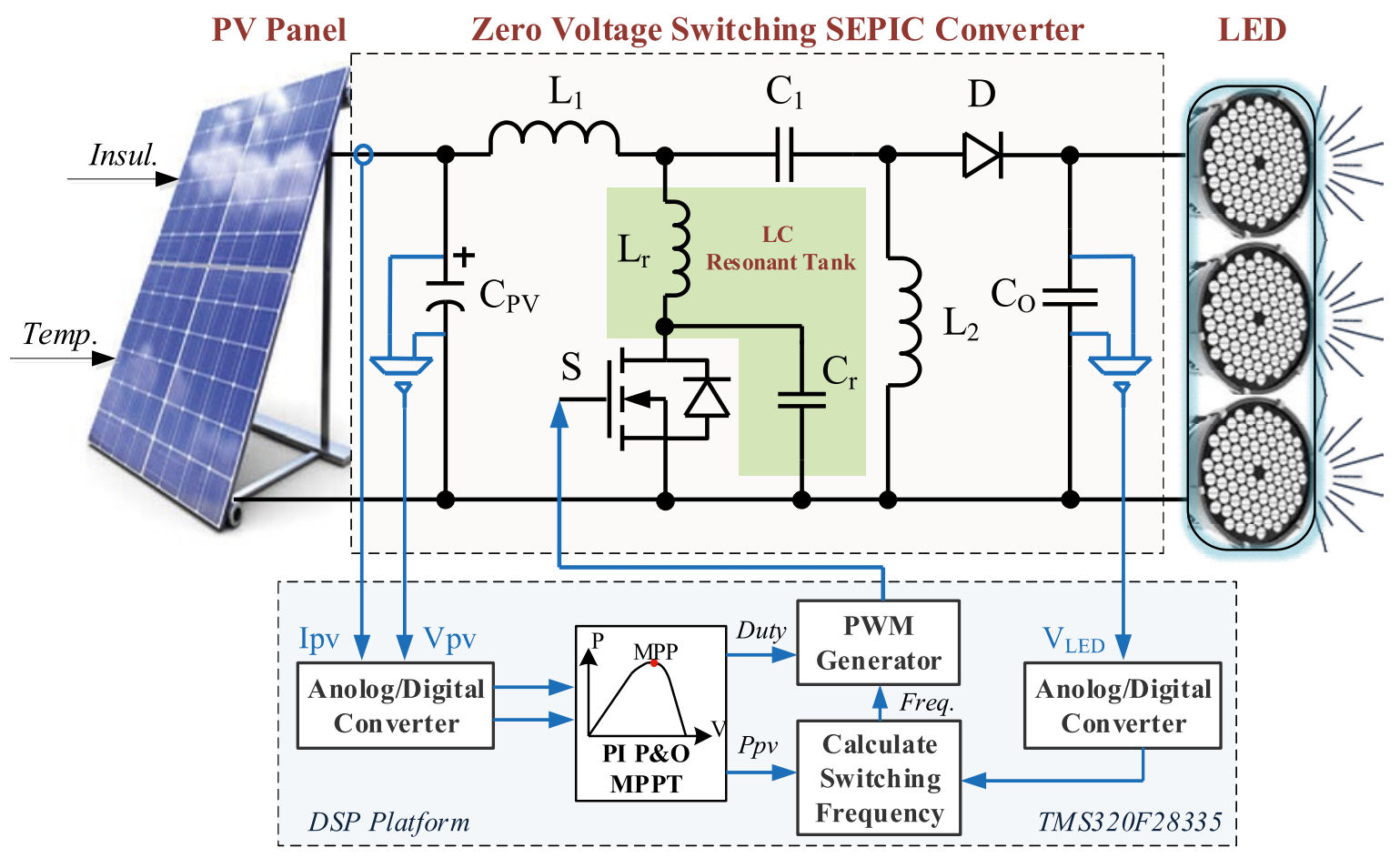

Fig. 1. The block diagram of the PV powered ZVS SEPIC converter for LED driver

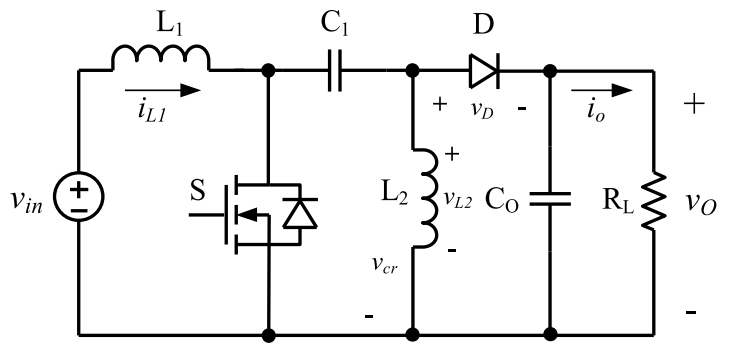

a)

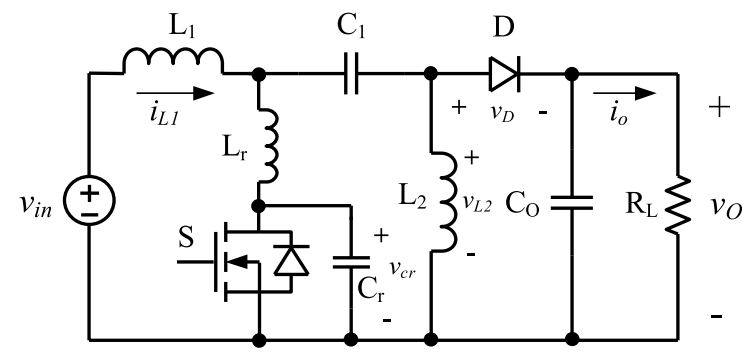

b)

Fig. 2. Conventional SEPIC (a), QR ZVS SEPIC (b)

switch. Soft switching at high switching frequencies are provided by low values of these resonance components. In ZVS topology, the switch operates at zero voltage. Therefore, switching losses are reduced to almost zero [22].

Conventional and Quasi-Resonant (QR) ZVS SEPIC are represented in Figs. $2 a, b$ respectively.

In this study, QR ZVS SEPIC structure was preferred. While the operation modes are important for a detailed analysis and understanding of such structure, Fig. 3 shows the operation modes of proposed QR ZVS SEPIC, where waveforms of operating modes given in Fig. 4.

Mathematical model can give detailed information for ZVS SEPIC. In this context, proposed model can be represented mathematically as follows.

The converter elements in the circuit are quite big compared to the resonance components and the circuit elements are considered ideal. Resonance frequency and characteristic impedance are given in Eq. (1) and Eq. (2), respectively.

$$
\begin{gathered}
\omega_{0}=\frac{1}{\sqrt{L_{r} C_{r}}}, \\
Z_{0}=\sqrt{\frac{L_{r}}{C_{r}}}=\omega_{0} L_{r}=\frac{1}{\omega_{0} C_{r}} .
\end{gathered}
$$

The normalized load resistance is given in Eq. (3).

$$
Q=\frac{R_{L}}{Z_{0}}=\frac{F R_{L}}{\omega_{s} L_{r}}=\frac{\omega_{s} C_{r} R_{L}}{F_{n}},
$$

where $F_{n}=f_{s} / f_{0}$ is the normalized switching frequency. Normalized resonance inductor initial current and switch initial current when switch is closed can be defined as: 


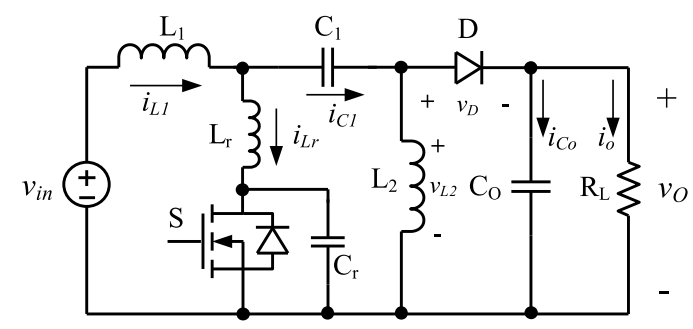

a)

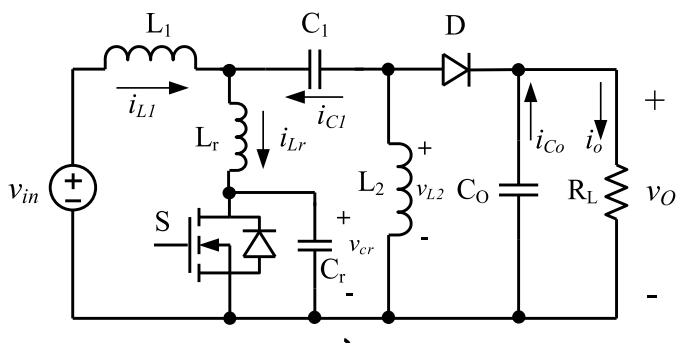

c)

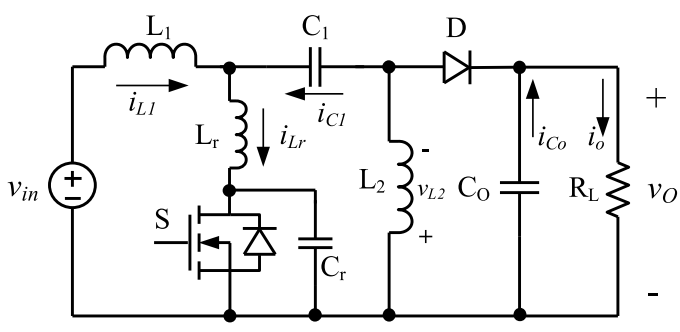

b)

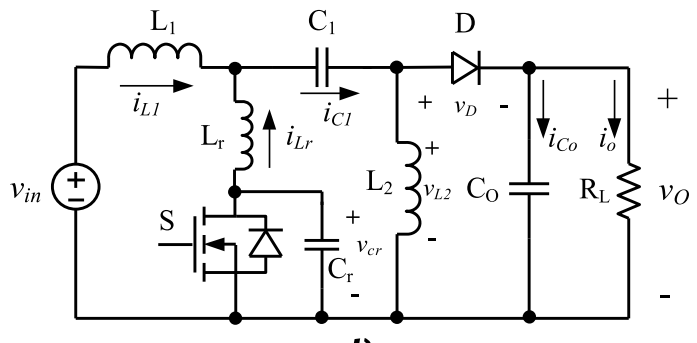

d)

Fig. 3. The operation modes of QR ZVS SEPIC: a) Mode 1, b) Mode 2, c) Mode 3, d) Mode 4

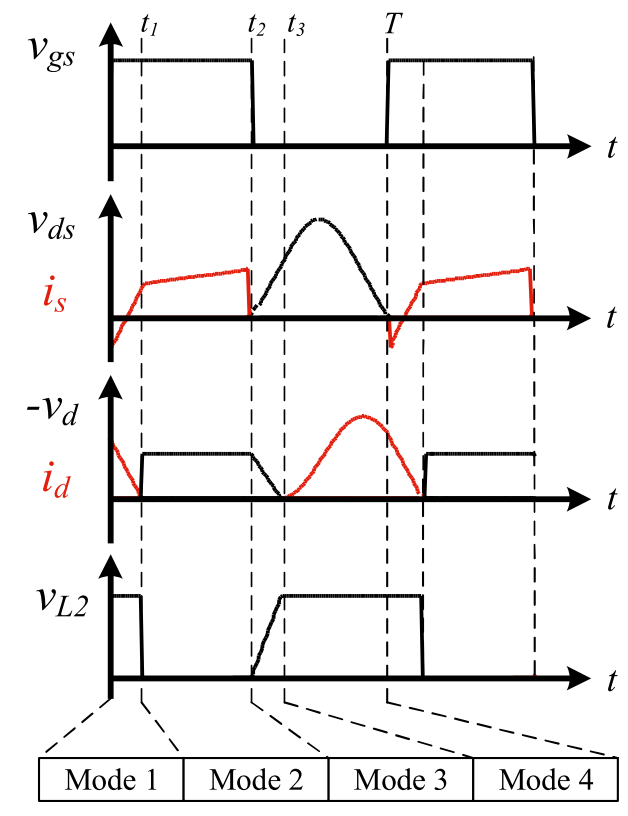

Fig. 4. Waveforms of QR ZVS SEPIC

$$
\lambda=\frac{i_{L_{r}}(0)}{I_{\text {in }}+I_{\text {out }}}=\frac{i_{s}(0)}{I_{\text {in }}+I_{\text {out }}} .
$$

\subsubsection{Mode $1\left(0<t<t_{1}\right)$}

In this mode, both the semiconductor switch and the diode are turned off.

While $V_{m}=V_{\text {out }} / V_{\text {in }}$ is voltage gain, the current flowing through the switch during this mode is:

$$
i_{s}=\frac{\left(I_{\text {in }}+I_{\text {out }}\right) Q \omega_{\mathrm{s}} t}{F_{n} V_{m}}+i_{s}(0) \text {. }
$$

Similarly, the current flowing through the diode $i_{d}$ is describing by Eq. 6 .

$$
i_{d}=I_{\text {in }}+I_{\text {out }}-\frac{\left(I_{\text {in }}+I_{\text {out }}\right) Q \omega_{\mathrm{s}} t}{F_{n} V_{m}}-i_{s}(0) .
$$

When the current flowing through the diode reaches zero, this mode ends instantly at " $t_{1}$ ".

\subsubsection{Mode $2\left(t_{1}<t<t_{2}\right)$}

In this mode, the semiconductor switch is on and the diode is off. The current flowing through the switch during this mode is

$$
i_{s}=I_{\text {in }}+I_{\text {out }} \text {. }
$$

Similarly, the diode voltage is

$$
v_{d}=-V_{\text {in }}-V_{\text {out }} \rightarrow-v_{d}=V_{\text {in }}+V_{\text {out }} .
$$

This mode ends at " $t_{2}$ " when the switch is opened by the gate driver.

\subsubsection{Mode $3\left(t_{2}<t<t_{3}\right)$}

In this mode, both the semiconductor switch and the diode are off. Switch voltage during this mode is

$$
v_{s}=\frac{V_{m}\left(V_{\text {in }}+V_{\text {out }}\right)}{F_{n} Q}\left(\omega_{\mathrm{s}} t-2 \pi D\right),
$$

where $D$ is the duty cycle. 


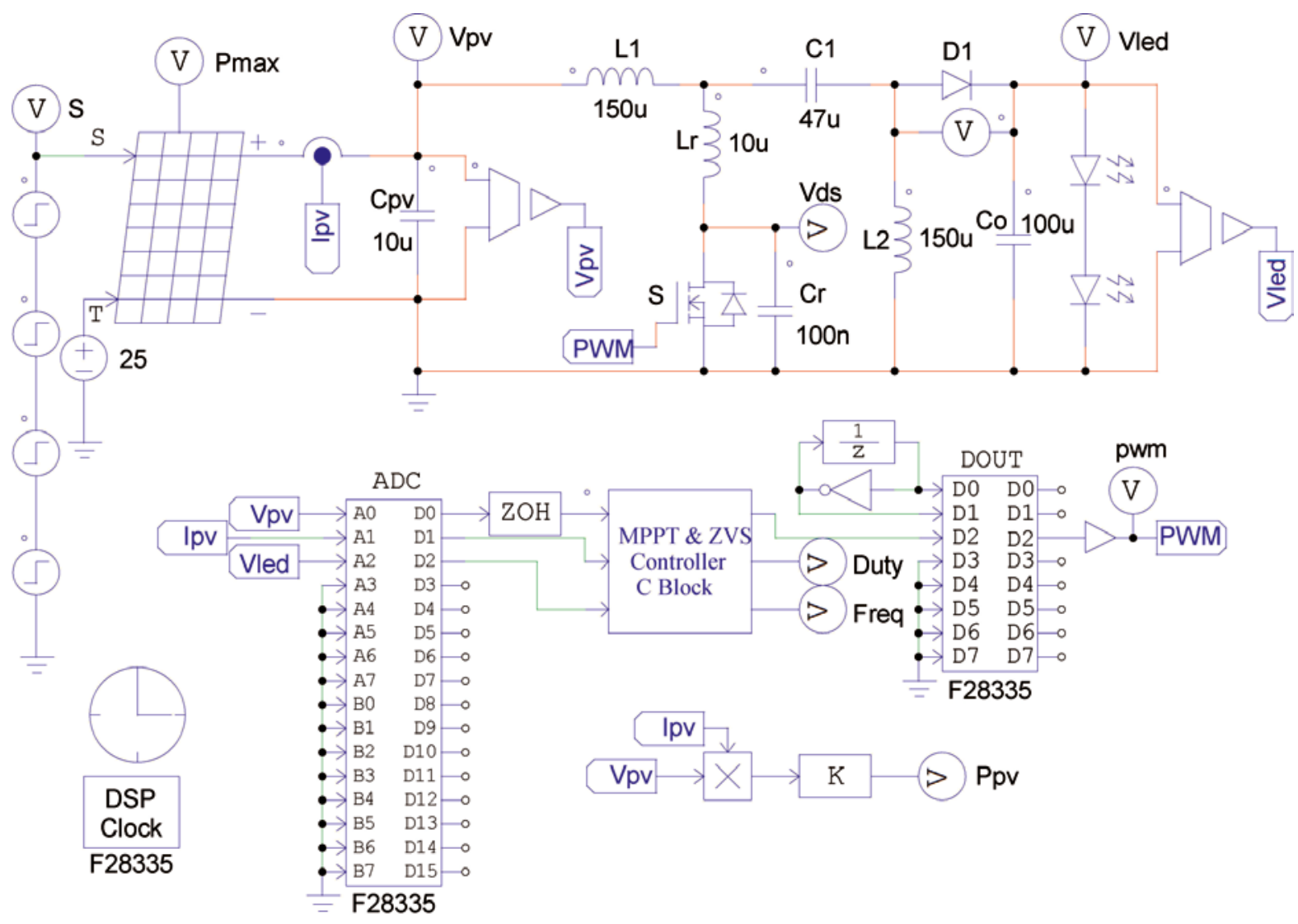

Fig. 5. PSIM circuit of PV fed ZVS SEPIC LED driver

Similarly, diode voltage is

$$
v_{d}=\left(V_{\text {in }}+V_{\text {out }}\right)\left(\frac{V_{m}}{F_{n} Q}\left(\omega_{\mathrm{s}} t-2 \pi D\right)-1\right) \text {. }
$$

This mode ends at " $t_{3}$ " when the diode voltage reaches zero.

\subsubsection{Mode $4\left(t_{3}<t<T\right)$}

In this mode, the semiconductor switch is off and the diode is on. Switch voltage during this mode is

$$
v_{s}=\left(V_{\text {in }}+V_{\text {out }}\right)\left(1+\frac{V_{m}}{Q} \sin \left(\frac{\omega_{\mathrm{s}} t-\omega_{\mathrm{s}} t_{3}}{F_{n}}\right)\right) \text {. }
$$

And diode current is

$$
i_{d}=\left(I_{\text {in }}+I_{\text {out }}\right)\left(1-\cos \left(\frac{\omega_{\mathrm{s}} t-\omega_{\mathrm{s}} t_{3}}{F_{n}}\right)\right) \text {. }
$$

The current flowing through the resonance inductor is calculated as given in Eq. (13):

$$
i_{L_{r}}=\left(I_{\text {in }}+I_{\text {out }}\right) \cos \left(\frac{\omega_{\mathrm{s}} t-\omega_{\mathrm{s}} t_{3}}{F_{n}}\right) .
$$

This mode ends at " $T$ " when the switch is closed by the gate driver.
For the ZVS operation, the equations (14) and (15) must be met:

$$
\begin{gathered}
v_{s}(T)=v_{s}(0)=0, \\
i_{L_{r}}(T)=i_{L_{r}}(0)=\lambda\left(I_{\text {in }}+I_{\text {out }}\right)=0 .
\end{gathered}
$$

Using Eq. (13), it can be written as:

$$
\frac{Q}{V_{m}}=-\sin \left(\frac{2 \pi(1-D)}{F_{n}}-\frac{Q}{V_{m}}\right) \text {. }
$$

Normalized initial switch current is determined using Eq. (4), (5), (13) and is given as in Eq. (17):

$$
\lambda=\cos \left(\frac{2 \pi(1-D)}{F_{n}}-\frac{Q}{V_{m}}\right) .
$$

Duty cycle is determined by using Eq. (16).

$$
\begin{gathered}
D=1-\frac{1}{2 \pi} F_{n} \times \\
\times\left(-\cos ^{-1}\left(\sqrt{1-\left(\frac{Q}{V_{m}}\right)^{2}}\right)+\frac{Q}{V_{m}}+2 \pi n\right) .
\end{gathered}
$$



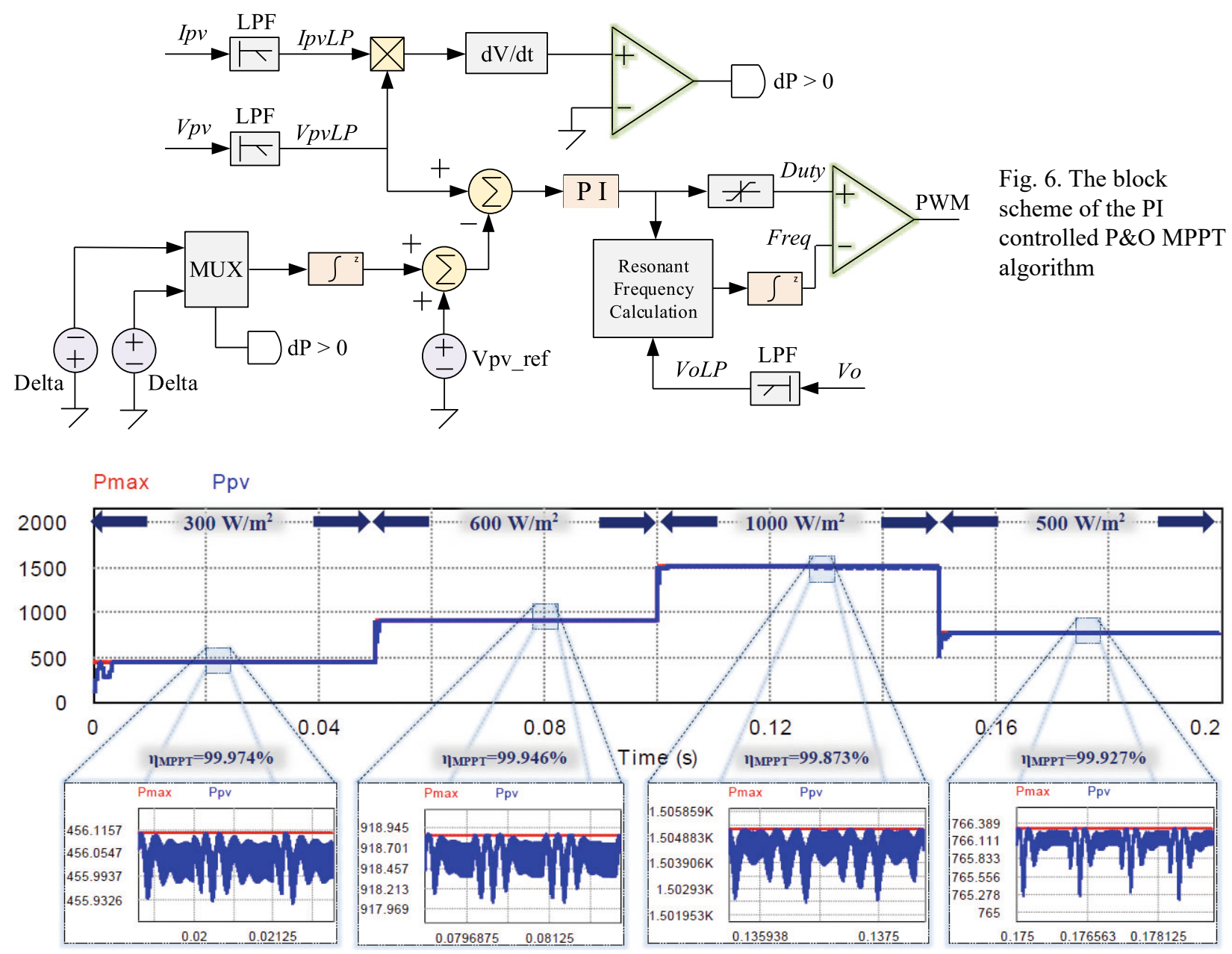

Fig. 7. Simulation results of the maximum power point tracking under different solar radiation

It is seen that the switching period has a fixed opening and variable closing time. For the ZVS process, the Eq. (19) must be obtained:

$$
-1 \leq \lambda \leq 1 \text { or } 0 \leq Q=\frac{R_{L}}{Z_{0}} \leq V_{m} \text {. }
$$

\subsection{PSIM Modelling of Driver Circuit}

The proposed SEPIC-based ZVS driver circuit which was designed under PSIM platform is shown in Fig. 5.

Table 1 shows parameters of circuit elements.

The PV panel used in the system was designed based on the TRP-250B model, which has a 60-cell structure. The parameters of the PV panel are given in Table 2.

\subsection{MPPT Algorithm}

Proposed model use an adaptive and efficient MPPT algorithm. Block representation of the PI controlled P\&O MPPT algorithm is given in Fig. 6 .
The PI controlled P\&O MPPT algorithm is written in the simplified $\mathrm{C}$ block in the PSIM program. PI controlled P\&O MPPT algorithm is realized by adjusting the reference voltage according to the power change. There may be interference in the current and voltage values measured from the PV panels. A low pass filter has been used in the system in order to eliminate these interferences and to track the MPP accurately. The difference of the reference voltage $\left(V_{p v \_r e f}\right)$ value obtained with the PV voltage passed through the filter gives the error value. The error voltage value is also passed through the PI controller to determine the duty ratio. If the power change is greater than zero, the duty ratio is increased by adding the delta value determined to the $V_{p v}$ value. If the power change is less than zero, the duty ratio is reduced by subtracting the delta value from the $V_{p v}$ value. According to the determined duty ratio, the switching frequency is calculated using Eq. (18) and the appropriate PWM signals are sent to the switch. Thus, maximum power is obtained from PV panels by PI controlled P\&O MPPT 
Table 1. Circuit Parameters

\begin{tabular}{|c|c|c|}
\hline Components & Parameters & Features \\
\hline$L_{1}$ & $150 \mu \mathrm{H}$ & $20 \mathrm{~m} \Omega$ \\
\hline$L_{2}$ & $150 \mu \mathrm{H}$ & $20 \mathrm{~m} \Omega$ \\
\hline$C_{P V}$ & $10 \mu \mathrm{F}$ & $10 \mathrm{~m} \Omega$ \\
\hline$C_{0}$ & $100 \mu \mathrm{F}$ & $30 \mathrm{~m} \Omega$ \\
\hline$C_{1}$ & $47 \mu \mathrm{F}$ & $20 \mathrm{~m} \Omega$ \\
\hline$R_{L E D}$ & $5 \Omega$ & - \\
\hline MOSFET & IXFK40N90P & $R_{D S o n}=230 \mathrm{~m} \Omega$, \\
\hline Diode & DSEP60-06A & $\begin{array}{c}V_{F}=1.39 \mathrm{~V}, r_{F}=7.1 \\
\mathrm{~m} \Omega\end{array}$ \\
\hline$L_{r}$ & $10 \mu \mathrm{H}$ & $2 \mathrm{~m} \Omega$ \\
\hline$C_{r}$ & $100 \mathrm{nF}$ & $5 \mathrm{~m} \Omega$ \\
\hline $\mathrm{f}_{\mathrm{o}}$ & $159 \mathrm{kHz}$ & - \\
\hline
\end{tabular}

Table 2. PV Panel Data

\begin{tabular}{|c|c|}
\hline PV Panel Parameters & $\begin{array}{c}\text { Standard Test } \\
\text { Conditions (STC) } \\
\left(\mathbf{1 0 0 0} \mathbf{~ W} / \mathbf{m}^{2}\right)\end{array}$ \\
\hline Maximum Power $\left(P_{\max }\right)$ & $250 \mathrm{~W}$ \\
\hline Ideal operating voltage $\left(V_{m p}\right)$ & $30.51 \mathrm{~V}$ \\
\hline Ideal operating current $\left(I_{m p}\right)$ & $8.25 \mathrm{~A}$ \\
\hline Short-circuit current $\left(I_{s c}\right)$ & $8.68 \mathrm{~A}$ \\
\hline Open-circuit voltage $\left(V_{o c}\right)$ & $36.50 \mathrm{~V}$ \\
\hline
\end{tabular}

method and maximum power can be transferred to LED luminaires.

\section{RESULTS AND DISCUSSION}

Proposed model was simulated under PSIM platform with different operating scenarios for validation. These scenarios consist of various irradiance levels as $300 \mathrm{~W} / \mathrm{m}^{2}, 600 \mathrm{~W} / \mathrm{m}^{2}, 1000 \mathrm{~W} / \mathrm{m}^{2}$, and $500 \mathrm{~W} / \mathrm{m}^{2}$, respectively. Performance of system was detailed by using graphs. In this context, simulation results of the maximum power point tracking performance of the PI-controlled P\&O MPPT algorithm that investigated by rapidly changing the solar radiation intensity were given in Fig. 7, where $P_{\max }$ is theoretical PV panel power and $P_{p v}$ is obtained $\mathrm{PV}$ panel power.

It is clear from Fig. 7 that the maximum power transfer continues dynamically even in sudden solar radiation changes. As seen in Fig. 8a, the duty
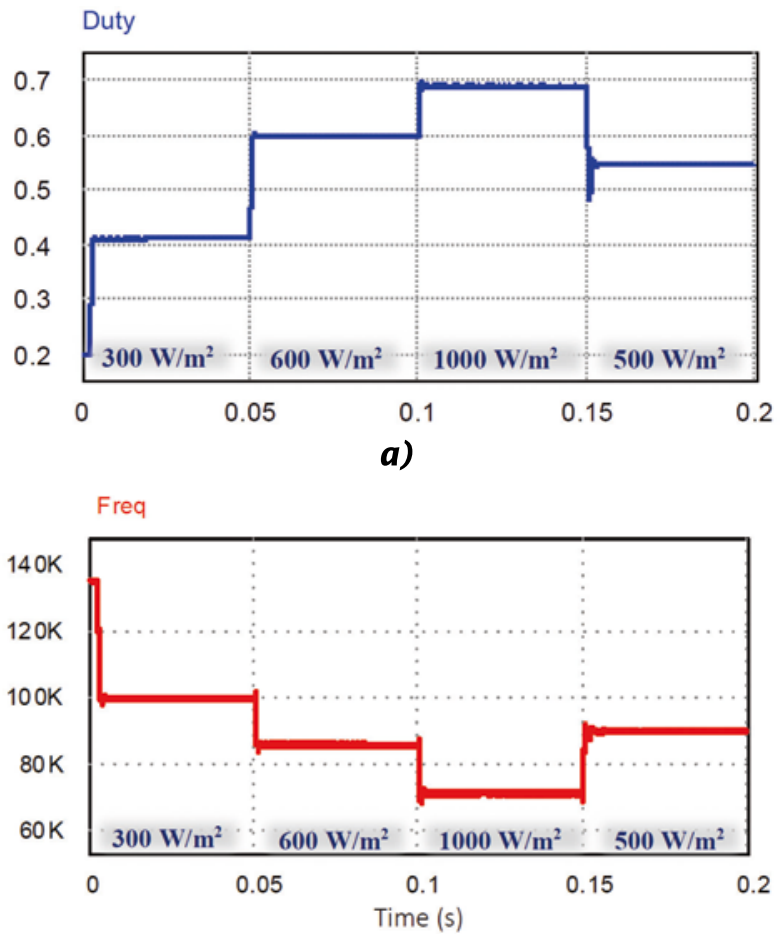

b)

Fig. 8. Simulation results under different solar radiation. a) Switching frequency, b) Duty ratio

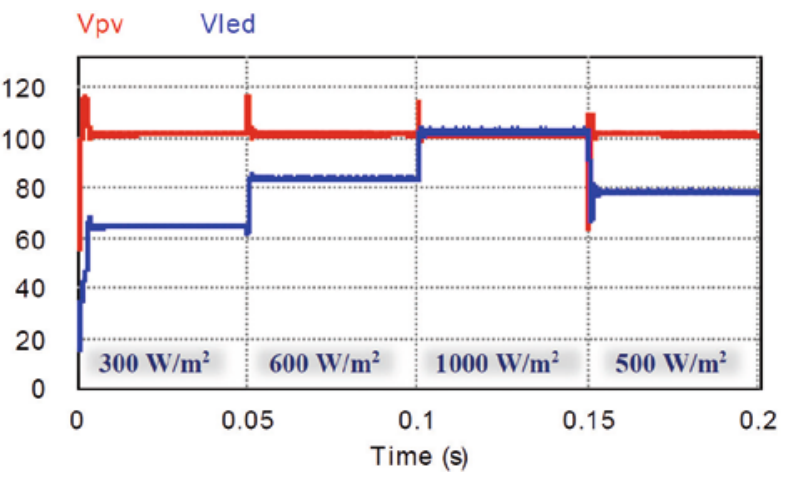

Fig. 9. Simulation results of the PV and LED array voltage under different solar radiation

ratio is changed rapidly in order to provide maximum power transfer at different radiation levels. Accordingly, due to the changing quality factor, as seen in Fig. 8b, the operating frequency has also been calculated and changed to ensure the ZVS conditions.

Fig. 9 shows the simulation results of the PV and LED array voltage under different solar radiation levels with $300 \mathrm{~W} / \mathrm{m}^{2}, 600 \mathrm{~W} / \mathrm{m}^{2}, 1000 \mathrm{~W} / \mathrm{m}^{2}$, and $500 \mathrm{~W} / \mathrm{m}^{2}$, respectively, where $V_{p v}$ is PV voltage and $V_{\text {led }}$ is voltage of LED luminaires.

The LED luminaire voltage is varying according to the value of the power obtained from the PV panels. While the voltage value supplied from PV pan- 


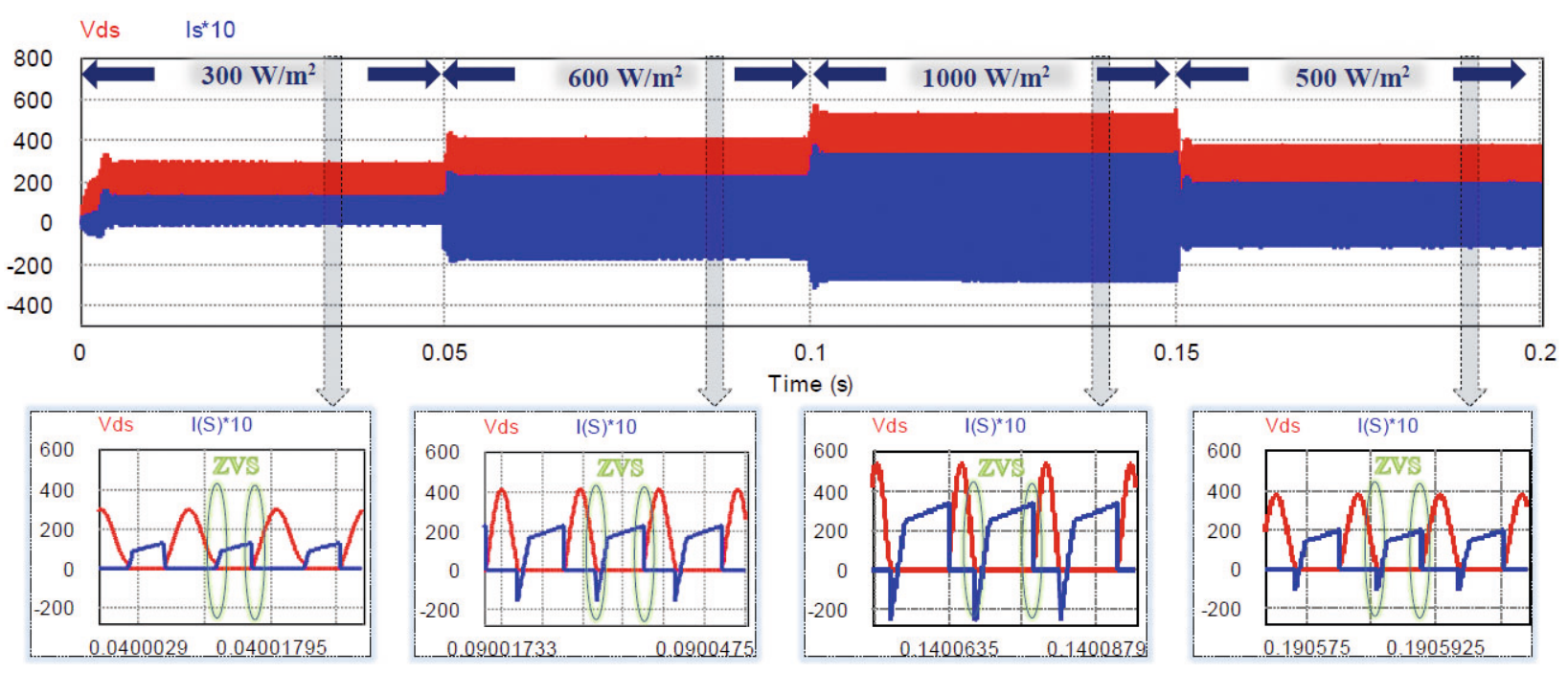

Fig. 10. Simulation results of the switch current and voltage under different solar radiation

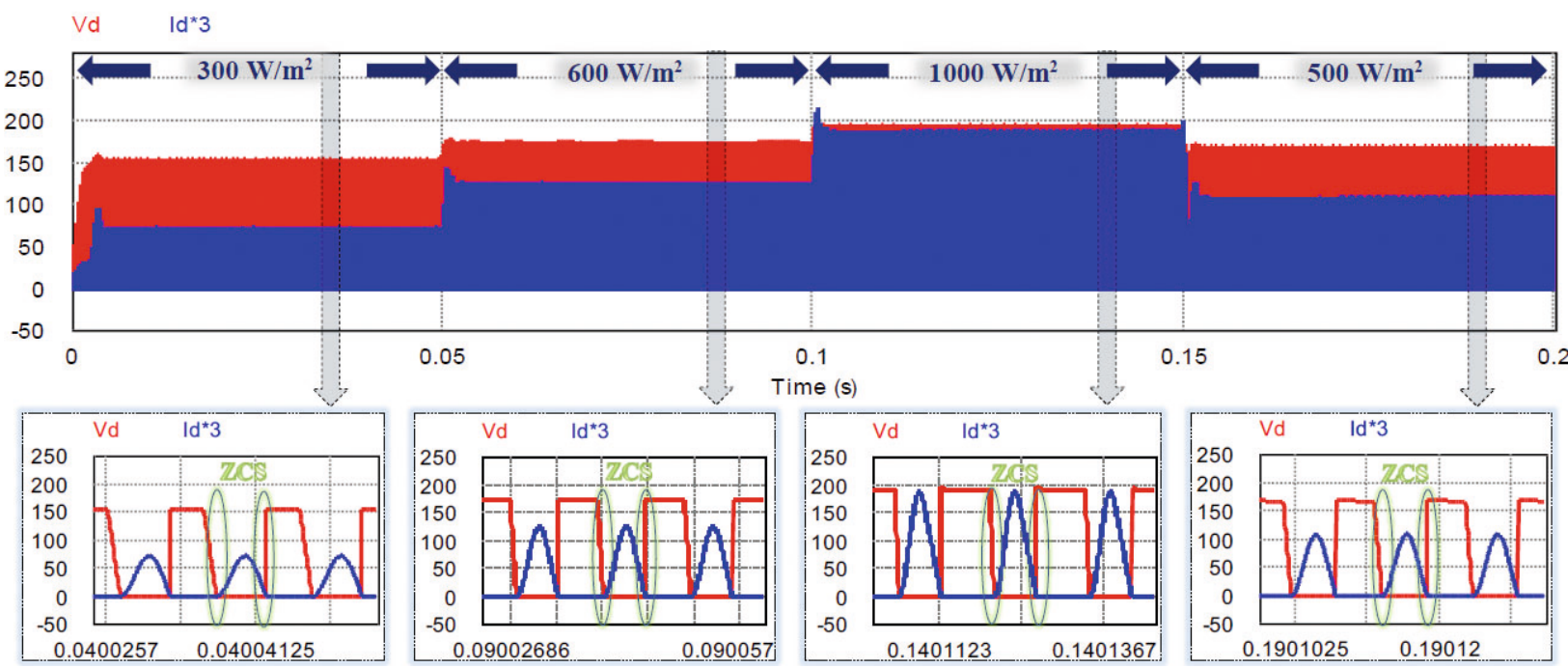

Fig. 11. Simulation results of the diode current and voltage under different solar radiation

els is around $100 \mathrm{~V}$, it is seen that the voltage on the LED group varies between $65 \mathrm{~V}$ and $104 \mathrm{~V}$.

Switch current and voltage are one of the most important parameters for ZVS applications. In addition, diode current and voltage values are necessary to be examined. Therefore their graphs should be analyzed in detail. According to this necessity, simulation results of the switch current and voltage under different solar radiation are given in Fig. 10. At different power values obtained from PV panels, the duty value and switching frequency are dynamically changed to provide ZVS. Thus, switching losses are minimized by switching at zero voltage for each power level.

Diode current and voltage graphs under different solar radiation of $300 \mathrm{~W} / \mathrm{m}^{2}, 600 \mathrm{~W} / \mathrm{m}^{2}, 1000 \mathrm{~W} / \mathrm{m}^{2}$, and $500 \mathrm{~W} / \mathrm{m}^{2}$, respectively, are given in Fig. 11 .
According to the results, when the current on the diode becomes zero, voltage starts to occur on the diode. Thus, the diode also works in the zero current switching (ZCS). In this way, switching losses on the diode are also minimized. It is clear that the switching component is successfully operated under ZVS conditions and diode under ZCS conditions under all solar radiation levels.

The total efficiency of the designed system under different solar radiation, which is one of the main performance indicators, is given in Fig. 12.

The simulation results for the PV powered ZVS SEPIC are given in Table 3.

It is clear from the graphs that proposed model has considerable advantages, which can be summarized as follows: 
Table 3. Simulation Results Under Various Solar Irradiation Levels

\begin{tabular}{|c|c|c|c|c|}
\hline Parameters & $\mathbf{3 0 0} \mathbf{W} / \mathbf{m}^{\mathbf{2}}$ & $\mathbf{6 0 0} \mathbf{~ W} / \mathbf{m}^{\mathbf{2}}$ & $\mathbf{1 0 0 0} \mathbf{W} / \mathbf{m}^{\mathbf{2}}$ & $\mathbf{5 0 0} \mathbf{W} / \mathbf{m}^{\mathbf{2}}$ \\
\hline PV Power $\left(P_{P V}\right)$ & $456 \mathrm{~W}$ & $918 \mathrm{~W}$ & $1505 \mathrm{~W}$ & $766 \mathrm{~W}$ \\
\hline PV Voltage $\left(V_{P V}\right)$ & $99.5 \mathrm{~V}$ & $100.5 \mathrm{~V}$ & $101 \mathrm{~V}$ & $100 \mathrm{~V}$ \\
\hline PV Current $\left(I_{P V}\right)$ & $4.583 \mathrm{~A}$ & $9.134 \mathrm{~A}$ & $14.9 \mathrm{~A}$ & $7.66 \mathrm{~A}$ \\
\hline LED Voltage $\left(V_{L E D}\right)$ & $64.9 \mathrm{~V}$ & $84.2 \mathrm{~V}$ & $103.5 \mathrm{~V}$ & $78.6 \mathrm{~V}$ \\
\hline Duty Ratio $(D)$ & 0.410 & 0.599 & 0.689 & 0.548 \\
\hline Switching Frequency $\left(f_{s}\right)$ & $100.1 \mathrm{kHz}$ & $86.2 \mathrm{kHz}$ & $71.3 \mathrm{kHz}$ & $90.2 \mathrm{kHz}$ \\
\hline MPPT Efficiency $\left(\eta_{M P P T}\right)$ & $99.974 \%$ & $99.946 \%$ & $99.873 \%$ & $99.927 \%$ \\
\hline System Efficiency $\left(\eta_{S Y S}\right)$ & $98.46 \%$ & $99.45 \%$ & $99.73 \%$ & $99.51 \%$ \\
\hline ZVS & $\checkmark$ & $\checkmark$ & $\checkmark$ & $\checkmark$ \\
\hline
\end{tabular}

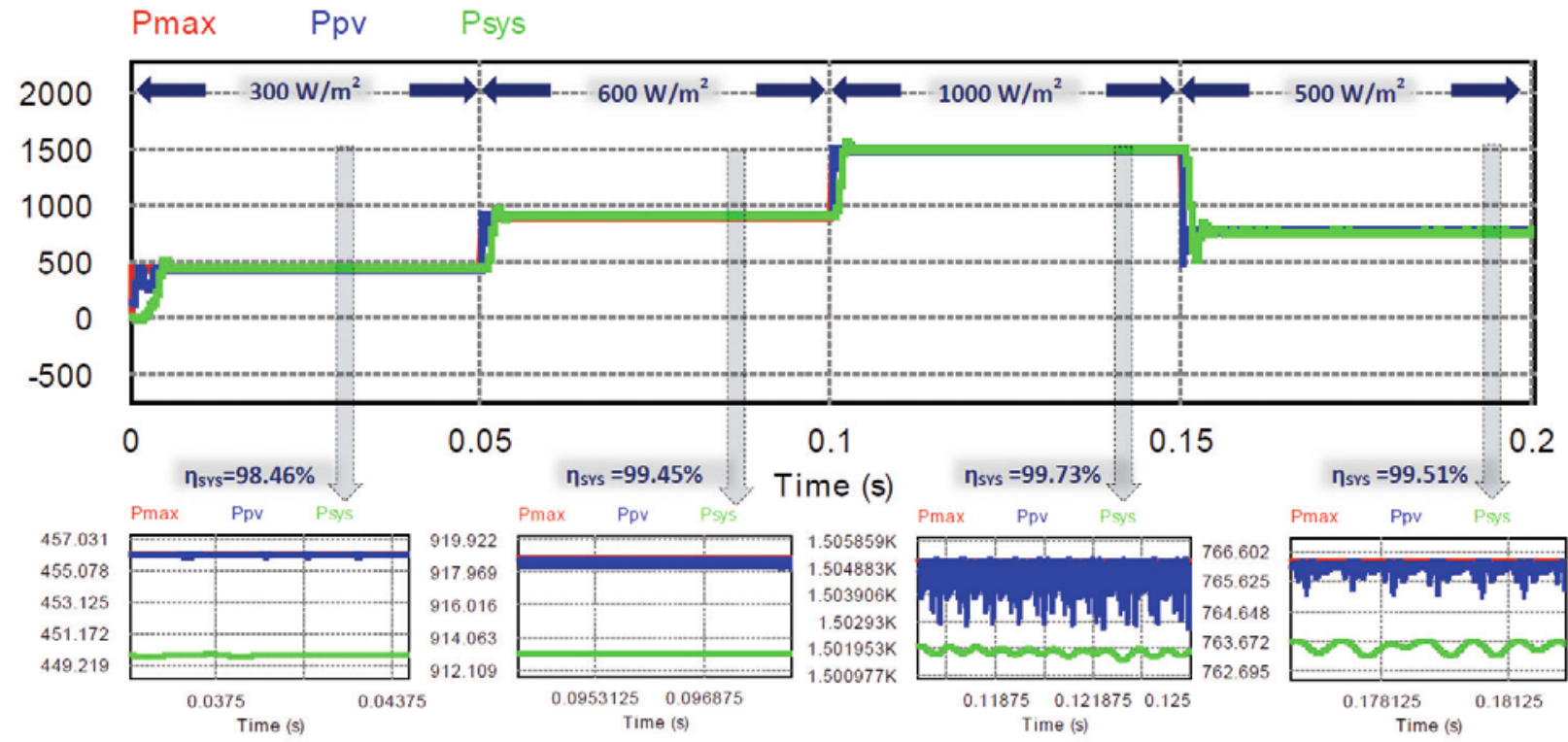

Fig. 12. The total efficiency of the designed system under different solar radiation

- In the designed ZVS SEPIC, MPP tracking has been carried out by working under continuous zero voltage switching conditions;

- It has been observed that the PI controlled P\&O MPPT algorithm tracking efficiency of the converter, operated in different solar radiation conditions, is high;

- It was operated at high frequency with low switching stress as a result of soft switching, and, by operating at high frequency, the volume of the circuit has been reduced due to the dimensions of the passive circuit components;

- By the ZVS SEPIC converter MPPT, the energy, obtained in the PV panels, was transferred to the LED luminaires with high efficiency.

In this study, the simulation study of the designed $1500 \mathrm{~W}$ LED driver system was verified in the PSIM program and the embedded code was generated for the TMS320F28335 processor. Thus, the infrastructure for the application of a high efficiency and high frequency LED driver system was formed. As a result of the designed system being of high frequency and operating under ZVS conditions with its quasi-resonant topology, the total dimensions of the system have been reduced and its efficiency has been increased. The dimensions of the LED driver system planned for the application are expected to be approximately $(200 \times 100 \times 50) \mathrm{mm}^{3}$ and $0.65 \mathrm{~kg}$ in weight.

\section{CONCLUSION}

In this paper an energy efficient driver for LED luminaires incorporation of ZVS SEPIC that supplied from PV panels via a developed MPPT algorithm was proposed. The energy obtained from PV 
panels operating in MPP under different solar radiation conditions is transferred to LED luminaires. The energy obtained from the PV panels constantly changes according to the environmental and load conditions. Therefore, MPPT with ZVS SEPIC has been used in order to achieve the highest possible output of $1500 \mathrm{~W}$ PV panel. In the study, the soft switched SEPIC MPPT was designed and simulated in order to increase the hard switching conditions and limited operating frequency in conventional PWM switched MPPTs. The power value required according to the MPPT algorithm was controlled by the PI-controlled P\&O method of the converter operating with zero voltage switching. With the implemented system, zero voltage switching conditions were created and high efficiency was successfully operated at frequencies above $70 \mathrm{kHz}$.

\section{REFERENCES}

1. Tikhonov P.V. Energy-Saving LED Lighting System with Parallel Power Supply by Photovoltaic Modules and by Network// Light \& Engineering,2020, Vol. 28, \# 6, pp. 36-40.

2. Ozbay H., Efe S.B., Özer İ. PV System Design for Farm Houses: A Case Study in Bandirma// Int. Eng. Nat. Sci. Conf. (IENSC2019), 2019, pp. 710-717.

3. Efe S.B., Varhan D. Interior Lighting of a Historical Building by using LED Luminaires: A Case Study of Fatih Paşa Mosque// Light \& Engineering, 2020, Vol. 28, \# 4, pp. 77-83.

4. Djuretic A., Kostic M. Actual energy savings when replacing high-pressure sodium with LED luminaires in street lighting// Energy, 2018, \#157, pp. 367-78. https://doi.org/10.1016/j.energy.2018.05.179.

5. Jiang Y., Li S., Guan B., Zhao G., Boruff D., Garg L., et al. Field evaluation of selected light sources for roadway lighting// J. Traffic Transp. Eng. (English Ed), 2018, \#5, pp. 372-385. https://doi.org/10.1016/j. jtte.2018.05.002.

6. Yoomak S., Ngaopitakkul A. Optimisation of lighting quality and energy efficiency of LED luminaires in roadway lighting systems on different road surfaces// Sustain Cities Soc., 2018, \#38, pp. 333-347. https://doi. org/10.1016/j.scs.2018.01.005.

7. Gerber D.L., Liou R., Brown R. Energy-saving opportunities of direct-DC loads in buildings// Appl. Energy, 2019, \# 248, pp. 274-287. https://doi.org/10.1016/j. apenergy.2019.04.089.

8. Nestyorkina N.P., Zhuravlyova Y.A., Kovalenko O.Y., Mikayeva S.A. Comparative Analysis of the
Characteristics of LED Filament Lamps for Household Lighting// Light \& Engineering, 2020, Vol. 28, \# 6, pp. 71-75.

9. Ayaz M., Yucel U., Erhan K., Ozdemir E. A Novel Cost-Efficient Daylight-Based Lighting System for Public Buildings: Design and Implementation// Light \& Engineering, 2020, Vol. 28, \# 6, pp. 60-70.

10. Elibol E., Ozmen O.T., Tutkun N., Kuysal O. Outdoor performance analysis of different PV panel types// Renew Sustain Energy Reviews, 2017, \# 67, pp. 651-661. https://doi.org/10.1016/j.rser.2016.09.051.

11. Hegedьs J., Hantos G., Poppe A. Light output stabilisation of LED based streetlighting luminaires by adaptive current control// Microelectron Reliab., 2017, \#79, pp. 448-456. https://doi.org/10.1016/j. microrel.2017.06.060.

12. Cengiz M.S., Yetkin S.. Thermal Analysis in Fixed, Flowed and Airless Environment for Cooling in LED Luminaires// Light \& Engineering,2020, Vol. 28, \# 6, pp. 28-35.

13. Huang B.J., Chen C.W., Ong C.D., Du B.H., Hsu P.C. Development of constant-power driving control for light-emitting-diode (LED) luminaire// Appl. Therm. Eng., 2013, \#50, pp. 645-651. https://doi.org/10.1016/j. applthermaleng.2012.07.030.

14. Karafil A., Ozbay H., Oncu S. Design and Analysis of Single-Phase Grid-Tied Inverter with PDM MPPTControlled Converter// IEEE Trans. POWER Electron, 2020, \# 35, pp. 4756-4766.

15. Jiang L.L., Srivatsan R., Maskell D.L. Computational intelligence techniques for maximum power point tracking in PV systems: A review// Renew Sustain Energy Rev., 2018, \#85, pp. 14-45. https://doi.org/10.1016/j. rser.2018.01.006.

16. Sheik Mohammed S., Devaraj D., Imthias Ahamed T.P. A Novel Hybrid Maximum Power Point Tracking Technique Using Perturb \& Observe Algorithm and Learning Automata for Solar PV System// Energy, 2016, \#112,1096-1106. https://doi.org/10.1016/j. energy.2016.07.024.

17. Majstorovic M., Mrsevic D., Duric B., Milesevic M., Stevic Z., Despotovic Z.V. Implementation of MPPT Methods with SEPIC Converter// 19th Int. Symp. INFOTEH-JAHORINA, INFOTEH 2020, pp. 1-6. https://doi.org/10.1109/INFOTEH48170.2020.9066296.

18. Necaibia S., Kelaiaia M.S., Labar H., Necaibia A., Castronuovo E.D. Enhanced auto-scaling incremental conductance MPPT method, implemented on low-cost microcontroller and SEPIC converter// Sol. Energy, 2019, \#180, pp. 152-168. https://doi.org/10.1016/j. solener.2019.01.028. 
19. Chiang S.J., Shieh H.J., Chen M.C. Modeling and control of PV charger system with SEPIC converter// IEEE Trans. Ind. Electron, 2009, \# 56, pp. 4344- 4353. https://doi.org/10.1109/TIE.2008.2005144.

20. Raj A., Arya S.R., Gupta J. Solar PV array-based DC-DC converter with MPPT for low power applications// Renew Energy Focus, 2020, \#34, pp. 109-119. https://doi.org/10.1016/j.ref.2020.05.003.
21. Unnikrishnan C.K., Raj C.R. High frequency quasi resonant SEPIC converter for wide range of operation// 2014 Int. Conf. Circuits, Power Comput. Technol. ICCPCT 2014, IEEE; 2014, pp. 984-989. https://doi. org/10.1109/ICCPCT.2014.7054958.

22. Oncu S, Ozbay H. Simulink model of parallel resonant inverter with DSP based PLL controller// Elektron Ir Elektrotechnika, 2015, \#21, pp. 14-17.
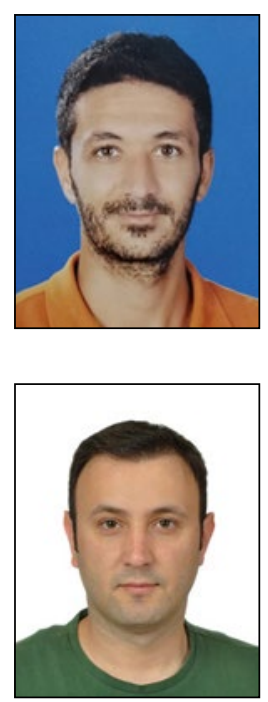

\section{Onur Akalp}

received his Master of Science degree from Dicle University, Turkey, in 2019. His main research areas are high voltage, power system analysis, power quality and renewable energy sources. He is currently working at TEİAS as electric engineer with the high voltage operating department

\section{Harun Ozbay}

received his B.S. degree in electrical education from Gazi University, Ankara, Turkey, in 2008, the M.S. degree in electrical education from Gazi University, Ankara, Turkey, in 2011, and Ph.D. degree in electrical and electronics engineering from Karabuk University, Karabuk, Turkey, in 2017. He is working with the Electrical Engineering Department, Bandırma Onyedi Eylül University, Balıkesir, Turkey, where he is currently an Assistant Professor. His research interests include power electronics, resonant converters, electric machines, grid-connected inverters, electric power systems, artificial intelligence, LED drivers, PV system applications, MPPT, electric vehicles and battery charger

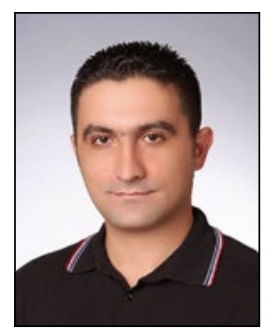

\section{Serhat Berat Efe}

received his $\mathrm{Ph}$. D. degree from Frrat University, Turkey, in 2014. His main research areas are power system analysis, power quality and renewable energy sources. He is currently working at Bandırma Onyedi Eylül University as Assistant Professor with the Electrical Engineering department 